\title{
Prevalence of Birth Defects among Neonates Born at the Philippine General Hospital from 2011 to 2014
}

\author{
Ebner Bon G. Maceda ${ }^{1}$ and Maria Melanie Liberty B. Alcausin ${ }^{1,2}$ \\ ${ }^{1}$ Department of Pediatrics, College of Medicine and Philippine General Hospital, University of the Philippines Manila \\ Institute of Human Genetics, National Institutes of Health, University of the Philippines Manila
}

\begin{abstract}
Objective. The study aimed to determine the prevalence of birth defects among neonates born at the Philippine General Hospital (PGH) from January 2011 to December 2014.

Methods. Monthly censuses of all deliveries from January 2011 to December 2014 were obtained from the Section of Newborn Medicine. All deliveries with birth defects were coded using International Classification of Diseases-10 (ICD -10). The codes were tallied and classified as either an isolated, part of a recognizable syndrome, chromosomal syndrome or multimalformed case (MMC). Period prevalence was then calculated.
\end{abstract}

Results. There was a total of 20,939 deliveries from 2011 to 2014 in PGH, of which 574 babies (2.74\%) had a diagnosis of at least one birth defect. Two-hundred seventy-three babies $(47.56 \%)$ had isolated defects; 130 (22.65\%) with defects in MMC; 106 (18.47\%) with defects as part of recognizable syndromes; and 65 (11.32\%) with defects as part of chromosomal syndromes. One in 36 births has at least one birth defect, which is higher than that reported in other Asian countries.

Conclusion. Birth defects are significant causes of morbidity and mortality. Results of this study provide baseline data that can be used for future studies on the causation of such birth defects, and can be used to formulate policies on primary and secondary prevention. For a tertiary hospital like PGH, these data can serve as a guide towards allocation of resources and manpower towards the more common birth defects.

Key Words: birth defects, congenital anomalies, neonates

\section{Introduction}

The World Health Organization defines birth defects or congenital disorders as structural or functional abnormalities, including metabolic disorders, which are

Presented at the 53rd Annual Convention of the Philippine Pediatric Society, Inc., April 2016, Philippine International Convention Center, and at the 28th International Congress of Pediatrics, August 2016, Vancouver, British Columbia, Canada.

Corresponding author: Ebner Bon G. Maceda, MD

Department of Pediatrics

Philippine General Hospital

University of the Philippines Manila

Taft Avenue, Ermita, Manila 1000 Philippines

Telephone: +6325261710

Email: egmaceda@up.edu.ph present from birth. These can cause spontaneous abortions and stillbirths and as a group, is a significant but under recognized cause of mortality and disability among infants and children under five years of age. ${ }^{1}$ Birth defects may be a result of single gene defects, chromosomal disorders, multifactorial inheritance, environmental teratogens, and micronutrient deficiencies. Infectious diseases like syphilis and rubella are significant causes of birth defects in low- and middle-income countries, like the Philippines. Maternal illnesses like diabetes mellitus, iodine deficiency are also other causes of birth defects. However, about $70 \%$ of the causes of birth defects are still unknown. ${ }^{1}$

Many environmental factors have been suspected to play an etiologic role in the formation of congenital anomalies, including chemical pollutants, dietary imbalances, ionizing radiation, pharmaceutical substances and infections. One of the dietary factors is folic acid deficiency, which is implicated in neural tube defects (NTDs). In a literature review in 2011 on the economic burden of NTDs, it was concluded that the benefits of preventing this condition with folic acid outweigh the costs. ${ }^{2}$

The presence of birth defects is one of the leading causes of pediatric disability and mortality in both developed and developing nations. In the United States, birth defects have been the leading cause of infant mortality in 1995 accounting for $21 \%$ of all infant deaths. A report of the Center for Disease Control (CDC) in the United States of America of a study looking at births in Atlanta from 1978 to 2005 showed that 1 in 33 births had a major birth defect. ${ }^{3}$ In Malaysia, prevalence of birth defects was 1 in 70 , with an incidence of 14.3/1000 births. $^{4}$ In Singapore, the prevalence of birth defects is $15 / 13$ per 1,000 live births. ${ }^{5}$

In the Philippines, birth defects or congenital anomalies have been consistent in the top ten causes of infant mortality for the past 50 years. Surveillance efforts in the Philippines started in 1999, when the Department of Health (DOH), in partnership with the Institute of Human Genetics - National Institutes of Health (IHG-NIH), University of the Philippines Manila conducted a pilot project of the Birth Defects Registry. It was noted that from 79 hospitals across the archipelago, 1240 birth defects cases were present from 191,576 newborns examined in 1999, with an incidence of 6 cases per 1000 person-years. The top birth defects in this study include (1) multiple congenital anomalies, 
congenital malformations of tongue, mouth, and pharynx, (3) cleft lip with cleft palate, (4) Down Syndrome, and (5) congenital malformations of the feet. ${ }^{6}$

At the Philippine General Hospital (PGH), the largest tertiary and referral hospital in the country, prevalence of structural birth defects was at $2 \%$ from a total of 438,944 admission from 2001 to 2010 . Subjects in this study included all age groups and not just newborns and thus the bias of increased number of non- fatal congenital anomalies were seen. Still, this study showed that the most common birth defects involve digestive, cardiovascular, nervous system, and genital organ anomalies which is a trend is similar to those reported in international papers. ${ }^{7}$

Despite the general decline in infant and child mortality rates in most Southeast Asian countries, mostly attributed to improved public health efforts in eradicating many infectious diseases and addressing malnutrition, the number of birth defects or congenital anomalies leading to disability and mortality remained constant. To meet the goal of further decreasing infant and child mortality rates, efforts to address non- communicable conditions need to be intensified. For birth defects, in order to initiate preventive programs, the first step is to generate epidemiological data. ${ }^{1}$

Whereas previous local studies covered all ages, this study aimed to determine the prevalence of structural birth defects among neonates born at the PGH. Although case detection among neonates will not provide us data on birth defects which are evolving and detected at later age, it will give us better results with respect to a general overview of all birth defects detected at birth, including those birth defects which will not prompt consult at later ages.

\section{Methods}

\section{Description of the Study Setting}

The PGH is a state-owned hospital with a 1,500-bed capacity. The section of newborn medicine accommodates an average of 500 deliveries a month. Being a referral center, it caters to patients needing subspecialty care from other institutions all over the archipelago.

\section{Data Collection}

All live births at the PGH from January 2011 to December 2014 and reported to have structural birth defects were included in this study. Monthly censuses of all deliveries were obtained from the Section of Newborn Medicine.
Stillbirths and spontaneous abortions were not included. Metabolic and/or inherited diseases and functional defects without obvious structural anomalies (e.g., congenital hypothyroidism) were also excluded.

International Classification of Diseases-10 (ICD-10) was used to classify birth defects. This classifies birth defects as "congenital malformations, deformations and chromosomal abnormalities" or Q00-Q99. Cases classified under Amnion Rupture Sequence ( $P$ 02.8) and Congenital Rubella Syndrome (P35.0) were included in the study.

\section{Data Analysis}

All cases of birth defects were reviewed by the investigator (EM). Birth defects were coded and classified as either an isolated defect, associated defect in multimalformed case (MMC), defects as part of a recognizable syndrome, and defects as part of a recognizable chromosomal syndrome. Period prevalence was calculated annually, from January 2011 to December 2014. It was obtained by dividing the total number of cases of birth defects yearly over the total number of deliveries yearly.

\section{Results}

\section{General Findings}

There was a total of 20, 939 deliveries from 2011 to 2014. Of which, 574 babies (2.74\%) had a diagnosis of at least one birth defect. Table 1 shows the total number of deliveries per year and the occurrence of birth defects per 10,000 deliveries.

Table 2 shows the number of birth defects by ICD-10 classification. There are subjects who have two or more defects, which cannot be classified under a recognizable syndrome or under part of chromosomal syndrome. Hence, a total of 934 birth defects were identified and counted. Of the 574 babies with birth defects, 273 (47.56\%) have isolated defects; 130 (22.65\%) have associated defects in multimalformed cases (MMC); 106 (18.47\%) have defects that are part of recognizable syndromes; and 65 (11.32\%) have defects as part of chromosomal syndromes.

There were 106 cases of recognizable syndromes comprising $18.5 \%(106 / 574)$ of all babies with birth defects. The most common recognizable syndrome identified was hydrops fetalis at $5.9 \%(34 / 574)$. This is followed by Arnold Chiari Malformation $3.8 \% \quad(22 / 574)$, thanatophoric dysplasia $1.2 \%(7 / 574)$ and Potter Sequence 1.0\% (6/574), respectively.

Table 1. Total Number of Neonates Born and Birth Defects Cases delivered at the Philippine General Hospital from January 2011 to December 2014

\begin{tabular}{|c|c|c|c|}
\hline Year & Total Number of Neonates Born & $\begin{array}{c}\text { Total Number of Neonates Born } \\
\text { with Birth Defects }\end{array}$ & $\begin{array}{l}\text { Occurrence of Patients } \\
\text { with Birth Defects per } 10,000 \text { deliveries }\end{array}$ \\
\hline 2011 & 5788 & 128 & 221 \\
\hline 2012 & 5119 & 137 & 268 \\
\hline 2013 & 4692 & 119 & 254 \\
\hline 2014 & 5340 & 190 & 356 \\
\hline TOTAL & 20,939 & 574 & 274 \\
\hline
\end{tabular}


There were 65 cases of chromosomal anomalies comprising $11.3 \%(65 / 574)$ of all patients with birth defects. In this series, $46.2 \%$ of which (30/65) have Down Syndrome. The other 35 patients (53.8\%) had either Edward or Patau Syndrome.

There were 273 isolated birth defects $(47.56 \%)$. The most common organ systems with isolated birth defects include musculoskeletal system (77/273), nervous system (75/273), and digestive system (50/273). However, 22\% (130/574) of all the birth defects cases were associated with an MMC. Of the 130 cases, there were a total of 490 birth defects counted. The most common organ systems associated with an MMC include musculoskeletal system (172/490), nervous system (71/490), and cardiovascular system (57/490).
The leading birth defects by system are musculoskeletal system anomalies. Congenital anomalies of the feet include mostly of clubfoot, rocker bottom feet and overlapping digits. Congenital malformations of the musculoskeletal system, not elsewhere classified (Q79) include gastroschisis, omphalocoele, congenital diaphragmatic hernia, and congenital diaphragmatic eventration. The second most common birth defects are nervous system anomalies (Q03), such as congenital hydrocephalus, spina bifida, and anencephaly. This is followed by ear anomalies (Q17) like microtia, digestive system anomalies (Q37) such as esophageal atresia, cardiovascular system (Q21 \& Q24) like ventricular septal defects and chromosomal abnormalities (Q90 \& Q91) such as Down syndrome. Also included in the top ten is hydrops fetalis (P56/P83) as seen in Table 3.

Table 2. Frequency of Isolated Defects, Associated Defects in Multi Malformed Cases (MMC), defects as part of Recognizable Syndromes, and Defects as Part of Recognizable Chromosomal Syndromes using ICD-10 Classification among Neonates born at the Philippine General Hospital from 2011-2014

\begin{tabular}{|c|c|c|c|c|c|c|}
\hline ICD Code & $\begin{array}{l}\text { Isolated } \\
\text { Defects }\end{array}$ & $\begin{array}{c}\text { Associated } \\
\text { Defect in } \\
\text { MMC }\end{array}$ & $\begin{array}{c}\text { Part of } \\
\text { Recognizable } \\
\text { Syndromes } \\
\end{array}$ & $\begin{array}{c}\text { Part of } \\
\text { Chromosomal } \\
\text { Syndromes } \\
\end{array}$ & Total & $\begin{array}{c}\text { Occurrence } \\
\text { per } 10,000 \\
\text { deliveries }\end{array}$ \\
\hline Nervous System & 75 & 71 & 28 & 0 & 174 & 83.10 \\
\hline Q 00 Anencephaly & 17 & 2 & 0 & 0 & 19 & 9.07 \\
\hline Q 01 Encephalocoele & 6 & 8 & 0 & 0 & 14 & 6.69 \\
\hline Q 02 Microcephaly & 0 & 10 & 0 & 0 & 10 & 4.78 \\
\hline Q 03 Congenital hydrocephalus & 38 & 32 & 3 & 0 & 73 & 34.86 \\
\hline Q 04 Other congenital malformations of brain & 6 & 7 & 3 & 0 & 16 & 7.64 \\
\hline Q 05 Spina bifida & 6 & 11 & 0 & 0 & 17 & 8.12 \\
\hline Q 06 Other congenital malformations of spinal cord & 1 & 0 & 0 & 0 & 1 & 0.48 \\
\hline Q 07 Other congenital malformations of nervous system & 1 & 1 & 22 & 0 & 24 & 11.46 \\
\hline Eye Anomalies & 0 & 4 & 0 & 0 & 4 & 1.91 \\
\hline Q 11 Anophthalmos, microphthalmos and macrophthalmos & 0 & 2 & 0 & 0 & 2 & 0.96 \\
\hline Q 15 other congenital anomalies of eye & 0 & 2 & 0 & 0 & 2 & 0.96 \\
\hline Ear anomalies & 7 & 44 & 0 & 0 & 51 & 24.36 \\
\hline Q 17 other congenital malformations of ear & 7 & 40 & 0 & 0 & 47 & 22.45 \\
\hline Q 18 other congenital malformations of face and neck & 0 & 4 & 0 & 0 & 4 & 1.91 \\
\hline Cardiovascular System Anomalies & 21 & 57 & 2 & 0 & 80 & 38.21 \\
\hline Q 20 Congenital malformations of cardiac chambers and connections & 3 & 9 & 0 & 0 & 12 & 5.73 \\
\hline Q 21 Congenital malformations of cardiac septa & 8 & 16 & 2 & 0 & 26 & 12.42 \\
\hline Q 22 Congenital malformations of pulmonary and tricuspid valves & 1 & 2 & 0 & 0 & 3 & 1.43 \\
\hline Q 23 Congenital malformations of aortic and mitral valves & 1 & 0 & 0 & 0 & 1 & 0.48 \\
\hline Q 24 Other congenital malformations of heart & 7 & 19 & 0 & 0 & 26 & 12.42 \\
\hline Q 25 Congenital malformations of great arteries & 0 & 7 & 0 & 0 & 7 & 3.34 \\
\hline Q 26 Congenital malformations of great veins & 0 & 1 & 0 & 0 & 1 & 0.48 \\
\hline Q 27 Other congenital malformations of peripheral vascular system & 1 & 3 & 0 & 0 & 4 & 1.91 \\
\hline Respiratory System Anomalies & 3 & 10 & 0 & 0 & 13 & 6.21 \\
\hline Q 30 Congenital malformations of nose & 0 & 6 & 0 & 0 & 6 & 2.87 \\
\hline Q 33 Congenital malformations of lung & 0 & 2 & 0 & 0 & 2 & 0.96 \\
\hline Q 34 Other congenital malformations of respiratory system & 3 & 2 & 0 & 0 & 5 & 2.39 \\
\hline Digestive System Anomalies & 50 & 54 & 0 & 0 & 104 & 49.67 \\
\hline Q 35 Cleft palate & 1 & 1 & 0 & 0 & 2 & 0.96 \\
\hline Q 36 Cleft lip & 4 & 0 & 0 & 0 & 4 & 1.91 \\
\hline Q 37 Cleft palate with cleft lip & 34 & 12 & 0 & 0 & 46 & 21.97 \\
\hline Q 38 Other congenital malformations of tongue, mouth and pharynx & 1 & 17 & 0 & 0 & 18 & 8.60 \\
\hline Q 39 Congenital malformations of esophagus & 0 & 4 & 0 & 0 & 4 & 1.91 \\
\hline Q 40 Other congenital malformations of upper alimentary tract & 0 & 1 & 0 & 0 & 1 & 0.48 \\
\hline Q 41 Congenital absence, atresia and stenosis of small intestine & 4 & 2 & 0 & 0 & 6 & 2.87 \\
\hline Q 42 Congenital absence, atresia, and stenosis of large intestine & 0 & 7 & 0 & 0 & 7 & 3.34 \\
\hline Q 43 Other congenital malformations of intestine & 1 & 1 & 0 & 0 & 2 & 0.96 \\
\hline Q 44 Congenital malformations of gallbladder, bile ducts, and liver & 0 & 1 & 0 & 0 & 1 & 0.48 \\
\hline Q 45 Other congenital malformations of digestive system & 5 & 8 & 0 & 0 & 13 & 6.21 \\
\hline
\end{tabular}




\begin{tabular}{|c|c|c|c|c|c|c|}
\hline ICD Code & $\begin{array}{l}\text { Isolated } \\
\text { Defects }\end{array}$ & $\begin{array}{l}\text { Associated } \\
\text { Defect in } \\
\text { MMC }\end{array}$ & $\begin{array}{c}\text { Part of } \\
\text { Recognizable } \\
\text { Syndromes }\end{array}$ & $\begin{array}{c}\text { Part of } \\
\text { Chromosomal } \\
\text { Syndromes }\end{array}$ & Total & $\begin{array}{c}\text { Occurrence } \\
\text { per 10,000 } \\
\text { deliveries }\end{array}$ \\
\hline Genital Organ Anomalies & 18 & 20 & 0 & 0 & 38 & 18.15 \\
\hline Q 52 Other congenital malformations of female genitalia & 0 & 2 & 0 & 0 & 2 & 0.96 \\
\hline Q 53 Undescended testicle & 0 & 5 & 0 & 0 & 5 & 2.39 \\
\hline Q 54 Hypospadias & 12 & 3 & 0 & 0 & 15 & 7.16 \\
\hline Q 55 Other congenital malformations of male genital organs & 6 & 10 & 0 & 0 & 16 & 7.64 \\
\hline Urinary System Anomalies & 8 & 10 & 6 & 0 & 24 & 11.46 \\
\hline Q 60 Renal agenesis and other reduction defects of kidney & 0 & 0 & 6 & 0 & 6 & 2.87 \\
\hline Q 61 Cystic kidney disease & 2 & 2 & 0 & 0 & 4 & 1.91 \\
\hline Q 62 Congenital obstructive defects of renal pelvis and congenital malformations of ureter & 6 & 6 & 0 & 0 & 12 & 5.73 \\
\hline Q 63 Other congenital malformations of kidney & 0 & 1 & 0 & 0 & 1 & 0.48 \\
\hline Q 64 Other congenital malformations of urinary system & 0 & 1 & 0 & 0 & 1 & 0.48 \\
\hline Musculoskeletal System Anomalies & 77 & 172 & 13 & 0 & 262 & 125.13 \\
\hline Q 65 Congenital deformities of hip & 0 & 1 & 0 & 0 & 1 & 0.48 \\
\hline Q 66 Congenital deformities of feet & 14 & 62 & 0 & 0 & 76 & 36.30 \\
\hline Q 67 Congenital musculoskeletal deformities of head, face, spine and chest & 0 & 9 & 0 & 0 & 9 & 4.30 \\
\hline Q 69 Polydactyly & 9 & 2 & 0 & 0 & 11 & 5.25 \\
\hline Q 70 Syndactyly & 5 & 3 & 0 & 0 & 8 & 3.82 \\
\hline Q 71 Reduction defects of upper limb & 1 & 2 & 0 & 0 & 3 & 1.43 \\
\hline Q 72 Reduction defects of lower limb & 0 & 4 & 0 & 0 & 4 & 1.91 \\
\hline Q 73 Reduction defects of unspecified limb & 2 & 1 & 1 & 0 & 4 & 1.91 \\
\hline Q 74 Other congenital malformation of limb(s) & 0 & 9 & 0 & 0 & 9 & 4.30 \\
\hline Q 75 Other congenital malformations of skull and face bones & 0 & 49 & 2 & 0 & 51 & 24.36 \\
\hline Q 76 Congenital malformations of spine and bony thorax & 0 & 3 & 0 & 0 & 3 & 1.43 \\
\hline Q 77 Osteochondrodysplasia with defects of growth of tubular bones and spine & 1 & 0 & 7 & 0 & 8 & 3.82 \\
\hline Q 79 Congenital malformations of the musculoskeletal system, not elsewhere classified & 45 & 27 & 3 & 0 & 75 & 35.82 \\
\hline \multicolumn{7}{|l|}{ Others } \\
\hline & 2 & 15 & 0 & 0 & 17 & 8 \\
\hline Q 83 Congenital malformations of breast & 0 & 2 & 0 & 0 & 2 & 1 \\
\hline Q 84 Other congenital malformations of integument & 0 & 2 & 1 & 0 & 3 & 1 \\
\hline Q 85 Phakomatoses, not elsewhere classified & 1 & 0 & 0 & 0 & 1 & 0.48 \\
\hline Q 87 Other specified congenital malformation syndromes affecting multiple systems & 3 & 1 & 17 & 0 & 21 & 10 \\
\hline Q 89 Other congenital malformations, not elsewhere classified & 1 & 28 & 1 & 0 & 30 & 14.33 \\
\hline P 02.8 Newborn affected by other unspecified abnormalities of membranes & 0 & 0 & 2 & 0 & 2 & 1 \\
\hline P 35.0 Congenital Rubella Syndrome & 0 & 0 & 2 & 0 & 2 & 1 \\
\hline P56/P83 Hydrops fetalis & 0 & 0 & 34 & 0 & 34 & 16 \\
\hline Chromosomal Abnormalities & 0 & 0 & 0 & 75 & 75 & 35.82 \\
\hline Q 90 Down Syndrome & 0 & 0 & 0 & 30 & 30 & 14.33 \\
\hline Q 91 Edwards and Patau Syndrome & 0 & 0 & 0 & 35 & 35 & 17 \\
\hline TOTAL DEFECTS & 273 & 490 & 106 & 65 & 934 & \\
\hline TOTAL CASES & 273 & 130 & 106 & 65 & 574 & \\
\hline
\end{tabular}

Table 3. Top 10 Birth Defects among neonates born at the Philippine General Hospital from January 2011 to December 2014

\begin{tabular}{|c|c|c|c|c|c|c|c|}
\hline $\begin{array}{l}\text { ICD } \\
\text { Code }\end{array}$ & Diagnosis & $\begin{array}{c}\text { Isolated } \\
\text { Defect }\end{array}$ & $\begin{array}{c}\text { Associated } \\
\text { defect in } \\
\text { MMC }\end{array}$ & $\begin{array}{c}\text { Part of } \\
\text { Recognizable } \\
\text { Syndrome }\end{array}$ & $\begin{array}{c}\text { Part of } \\
\text { Chromosomal } \\
\text { Syndromes }\end{array}$ & Total & $\begin{array}{c}\text { Occurrence } \\
\text { per } 10,000 \\
\text { deliveries }\end{array}$ \\
\hline Q 66 & Congenital deformities of feet & 14 & 62 & 0 & 0 & 76 & 36.30 \\
\hline Q 79 & Congenital malformations of musculo-skeletal system, not elsewhere classified & 45 & 27 & 3 & 0 & 75 & 35.82 \\
\hline Q 03 & Congenital hydrocephalus & 38 & 32 & 3 & 0 & 73 & 34.86 \\
\hline Q 75 & Other congenital malformations of skull and face bones & 0 & 49 & 2 & 0 & 51 & 24.36 \\
\hline$\widehat{Q} 17$ & Other congenital malformations of ear & 7 & 40 & 0 & 0 & 47 & 22.45 \\
\hline Q 37 & Cleft palate with cleft lip & 34 & 12 & 0 & 0 & 46 & 21.97 \\
\hline Q 91 & Edwards and Patau Syndrome & 0 & 0 & 0 & 35 & 35 & 16.72 \\
\hline P56/P83 & Hydrops fetalis & 0 & 0 & 34 & 0 & 34 & 16.24 \\
\hline Q 90 & Down Syndrome & 0 & 0 & 0 & 30 & 30 & 14.33 \\
\hline Q 21 & Congenital malformations of cardiac septa & 8 & 16 & 2 & 0 & 26 & 12.42 \\
\hline Q 24 & Other congenital malformations of heart & 7 & 19 & 0 & 0 & 26 & 12.42 \\
\hline
\end{tabular}

The second most commonly involved organ system associated with birth defects is the nervous system. Congenital hydrocephalus is the most common birth defect of this system (73/174), followed by other congenital malformations of the nervous system which include mostly Arnold-Chiari Malformation (Q07.0). Significant number of cases also includes anencephaly (19/174) and spina bifida (16/174).

\section{Discussion}

Birth defects are significant causes of pediatric disability or morbidity. Our data show that one in 36 births have at least 1 birth defect, which is much higher from that seen in one study done in Malaysia, showing 1 in 70 deliveries. ${ }^{4}$ This however is closer to the 1:33 reported by US CDC. ${ }^{3}$

In the March of Dimes Report on Birth Defects in 2006, the 
top 5 birth defects include 1) Congenital Heart Diseases, 2) Neural Tube Defects, 3) Hemoglobinopathies, 4) Down Syndrome, 5) Glucose 6-Phosphate Dehydrogenase Deficiency. ${ }^{8}$ In this March of Dimes report, the Philippines had a prevalence of 52.9 birth defects per 1000 live births or 1 birth defect per 19 deliveries. ${ }^{8}$ This, however, include both structural and functional abnormalities. In our study, the prevalence of birth defects does not include inborn errors of metabolism or those birth defects detected by newborn screening.

Combining anencephaly (Q00), encephalocoele (Q01), and spina bifida (Q05) under neural tube defects, our data can be compared with the March of Dimes report. In this study, NTDs is the fifth most prevalent birth defect from 2011 to 2014. The prevalence is 24 per 10,000 deliveries. Prevalence of NTDs per WHO region varies: African (11.7 per 10,000 births), Eastern Mediterranean (21.9 per 10,000 births), European (9.0 per 10,000 births), Americas (11.5 per 10,000 births), South-East Asian (15.8 per 10,000 births), and Western Pacific (6.9 per 10,000 births). For the Western Pacific region, our prevalence is higher primarily because of the low percentage of countries reporting in the region $(33 \%) .^{8}$

In comparison with the study on birth defects in PGH from 2000-2010,7 which included birth defects in all admitted patients regardless of age, the cases obtained here are those observed during delivery, including the minor anomalies. Minor anomalies are birth defects with no major surgical or cosmetic importance. Many of these minor anomalies involve the musculoskeletal system, such as overlapping digits and sandal gap deformity. Hence, musculoskeletal system topped the list. In the previous study in PGH, most of the defects are the reason for consult. Many birth defects which are noted in the previous study in $\mathrm{PGH}^{7}$ are not seen in this study primarily because many are not noted at birth and babies may have been discharged even before symptoms that required a consult were recognized. This would include syndromes like Turner syndrome and Noonan syndrome, which would present in the adolescent period with short stature and amenorrhea. Other syndromes such as the mucopoly-saccharidoses like Hunter syndrome, which would not present at birth, can be missed. Primary immunodeficiencies, like Job syndrome and Wiskott-Aldrich syndrome, are also birth defects which may not be noted at birth.

In this retrospective study, it can be observed that the number of birth defects increased yearly from 2011 to 2014. There are several possible explanations for this. The doctors in training are now more active and competent in searching for birth defects as a result of the previous studies on birth defects in the institution. Prenatal services are also better in the detection of these birth defects.

With the data obtained, the hospital may use this study to allocate resources and improve training in more pressing and prevalent defects requiring further medical and surgical management. This study may also serve as baseline data to be used for future studies on the causation of such birth defects, and hence be used to formulate policies on primary and secondary prevention.

\section{Conclusion}

The results show that the most common birth defects are musculoskeletal, nervous, cardiovascular and chromosomal anomalies. These data are comparable to the data in international reports in terms of the most commonly involved organ systems with birth defects. Our data show that one in 36 births have at least 1 birth defect, which is comparable to the data gathered by the US CDC. With the data obtained, further studies must be done to look deeper into the causation of these defects in the Philippines. With this study showing the burden of the disease, practical strategies towards primary and secondary prevention of birth defects must be look into. For a tertiary hospital like the PGH, this data will serve as a guide towards allocation of resources and manpower towards the more common birth defects.

\section{Statement of Authorship \\ All authors have approved the final version submitted.}

\section{Author Disclosure}

All the authors declared no conflict of interest.

\section{Funding Source}

None.

\section{References}

1. World Health Organization, Centers for Disease Control and Prevention, All India Institute of Medical Science. Report of Regional Expert Group Meeting on Prevention of Birth Defects in Southeast Asia, Dec 13-15, 2011, New Delhi, India.

2. Yi Y, Lindemann M, Colligs A, Snowball C. Economic burden of neural tube defects and impact of prevention with folic acid: a literature review. Eur J Pediatr. 2011; 170(11):1391-400.

3. Centers for Disease Control and Prevention. Update on overall prevalence of major birth defects--Atlanta, Georgia, 1978-2005. MMWR Morb Mortal Wkly Rep. 2008; 57(1):1-5.

4. Thong MK, Ho JJ, Khatijah NN. A population-based study of birth defects in Malaysia. Ann Hum Biol. 2005; 32(2):180-7.

5. Thein MM, Koh D, Tan KL, et al. Descriptive profile of birth defects among livebirths in Singapore. Teratology. 1992; 46(3):277-84.

6. David-Padilla C, Cutiongco-dela Paz EM, Cavan BCV, et al. Establishment of the Philippine Birth Defects Surveillance. Acta Med Philipp. 2011; 45(4):12-9.

7. David-Padilla C, Dion-Berboso A, Abadingo M, et al. Occurrence of birth defects at the Philippine General Hospital. Acta Med Philipp. 2011; 45(4):20-9.

8. Christianson A, Howson CP, Modell B. March of Dimes Global Report on Birth Defects: The Hidden Toll of Dying and Disabled Children. White Plains, NY: March of Dimes Birth Defects Foundation; 2006. 